\title{
Mercuric Mercury and Methylmercury Complexes of Glutathione
}

\author{
GEORG A. NEVILLE* and TORBJÖRN DRAKENBERG
}

The Institute of Hygiene, University of Lund, Magle Stora Kyrkogata 12, S-223 50 Lund, Sweden and Organic Chemistry 2 and Physical Chemistry 2, Chemical Center, University of Lund, Box 740, S-220 07 Lund, Sweden

The preparation, isolation and characterization of mercury(II) complexes of glutathione from alcoholic aqueous media is described. With mercury(II) chloride, a complex having the composition of a double salt in the solid state, $\left(\mathrm{C}_{10} \mathrm{H}_{16} \mathrm{O}_{6} \mathrm{~N}_{3} \mathrm{~S}\right)_{2} \mathrm{Hg}_{2} \mathrm{Cl}(\mathrm{OH})(\mathrm{HCl})_{2}$, was obtained which on dissolution in water showed similar ${ }^{13} \mathrm{C}$ NMR spectral features as the complex, $\left(\mathrm{C}_{10} \mathrm{H}_{15} \mathrm{O}_{6} \mathrm{~N}_{8} \mathrm{~S}\right) \mathrm{Hg} \cdot \mathrm{H}_{2} \mathrm{O}$, obtained with mercury(II) acetate. By comparison with the complex, $\mathrm{C}_{10} \mathrm{H}_{16} \mathrm{O}_{6} \mathrm{~N}_{3} \mathrm{SHgCH}_{3}$, obtained with methylmercury chloride, these complexes appear to have 1:1 inner salt (or chelate) structures in solution. Evidence from ${ }^{13} \mathrm{C}$ NMR Fourier transform spectroscopy suggests that the co-ordination requirements of (mercuric) mercury bonded to sulphur are satisfied by chelation of the glycyl peptide nitrogen of glutathione. The results are discussed in relation to earlier polarographic and alkalimetric investigations and recent NMR studies of metal complexation by glutathione.

Glutathione, a true peptide, is found in the erythrocytes of whole blood and has a number of functions including protection of hemoglobin against oxidation by hydrogen peroxide. It acts as a prosthetic group of glyceraldehyde-phosphate dehydrogenase and as a coenzyme of glyoxalase. It is also believed that glutathione functions as a "sulfhydryl-preserver" in maintaining certain proteins (as sulfhydryl-containing enzymes) in the reduced state which is essential for their activity. ${ }^{1}$ Although the binding of mercury to human erythrocytes has been subjected to considerable investigation, ${ }^{2}$ little is known concerning the detailed molecular nature of binding. The binding is generally attributed to sulfhydryl groups of hemoglobin, glutathione and of stromal groups. ${ }^{3}$

* 1972 Centennial Fellow of the Medical Research Council of Canada. Present address: Health Protection Branch, Dept. National Health \& Welfare, Tunney's Pasture, Ottawa, Canada.

Acta Chem. Scand. B 28 (1974) No. 4
In a polarographic study of the reaction of mercuric mercury (acetate and chloride) with glutathione (RS), Stricks and Kolthoff obtained indirect evidence for the formation of three compounds with mercury: $\mathrm{Hg}(\mathrm{RS})_{\mathbf{2}}, \mathrm{Hg}_{2}$ $(\mathrm{RS})_{2}$, and $\mathrm{Hg}_{3}(\mathrm{RS})_{2}$ in the absence of chloride and in the $\mathrm{pH}$ range between 3 and 9 . In the presence of much chloride ion, the formation of the complexes $\mathrm{Hg}_{2}(\mathrm{RS})_{2}$ and $\mathrm{Hg}_{3}(\mathrm{RS})_{2}$ is suppressed by formation of the complex $\mathrm{HgCl}_{4}{ }^{2-}$. Similar conclusions were reached by Kapoor, Doughty and Gorin ${ }^{5}$ in their alkalimetric titration study of the reaction of $\mathrm{HgCl}_{2}$ with glutathione, however, with one exception, no precipitates were isolated and characterized. Kapoor et al. ${ }^{5}$ obtained a precipitate whose mercury content was found to be $49 \%$ by bringing a 3:2 $\mathrm{HgCl}_{2}$ /glutathione mixture to $\mathrm{pH}$. No other analyses were obtained on this substance and no structural features were proposed for it.

Recently Fuhr and Rabenstein ${ }^{\circ}$ reported on the nature of mercurial binding to glutathione in mercury(II) nitrate solutions using ${ }^{13} \mathrm{C}$ NMR spectroscopy, and Simpson, Hopkins and Haque ${ }^{7}$ reported on binding of methylmercury chloride to the model peptide, $N$-acetyl-L-cysteine, by means of a ${ }^{1} \mathrm{H}$ NMR study. In this paper, the isolation of mercury complexes of glutathione with mercury(II) acetate, mercury(II) chloride, and methylmercury chloride is reported together with the use of Fourier Transform ${ }^{13} \mathrm{C}$ NMR spectroscopy for their characterization.

\section{RESULTS AND DISCUSSION}

In contrast to the dilute aqueous conditions employed in polarographic and titrimetric investigations, ${ }^{4,5}$ mercury complexes were pre- 
pared and isolated in this study from alcoholic aqueous media moderately concentrated with reactants. Complete elemental analyses were obtained to establish empirical formulae. Recent work $^{8}$ in the characterization of hydrated mercury complexes of cysteine methyl ester serves to emphasize the value of complete elemental analysis including analysis for oxygen. FT ${ }^{13} \mathrm{C}$ NMR spectroscopy has been valuable for elucidating mercurial binding and configuration in isolated mercury complexes of methionine ${ }^{\circ}$ and of cysteine, $S$-methyl cysteine and cysteine methyl ester. ${ }^{10}$

The mercury(II) glutathionate complex prepared from mercury(II) acetate is devoid of acetate groups as shown by infrared spectra, microanalysis, and ${ }^{13} \mathrm{C}$ NMR spectra. Microanalysis provided elemental ratios in excellent agreement with the composition $\mathrm{C}_{10} \mathrm{H}_{17} \mathrm{O}_{7} \mathrm{~N}_{8} \mathrm{SHg}$ (M. W. 524.14) which could be formulated in terms of either a hydroxy complex, $\left(\mathrm{C}_{10} \mathrm{H}_{16} \mathrm{O}_{6} \mathrm{~N}_{3} \mathrm{~S}\right) \mathrm{Hg}$ $(\mathrm{OH})$, or as a hydrated inner salt (or chelate), $\left(\mathrm{C}_{10} \mathrm{H}_{15} \mathrm{O}_{6} \mathrm{~N}_{8} \mathrm{~S}\right) \mathrm{Hg} \cdot \mathrm{H}_{2} \mathrm{O}$. The consideration of a hydroxy complex is not unreasonable in view of crystallographic work by Johansson ${ }^{11}$ demonstrating a basic salt structure for mercury(II) perchlorate. Similarly, Björnlund ${ }^{12}$ has established that the compound previously formulated as $\mathrm{HgO} . \mathrm{Hg}\left(\mathrm{BrO}_{3}\right)_{2} \cdot \mathrm{H}_{2} \mathrm{O}$ is, in reality, $\mathrm{Hg}(\mathrm{OH})$ $\mathrm{BrO}_{3}$. Unfortunately, the three complexes reported here were shown to be amorphous by $\mathrm{X}$-ray diffraction. Attempts to grow crystals at moderate temperature $\left(120^{\circ} \mathrm{C}\right)$ from mercurysulphur containing complexes in the presence of their mother liquors resulted in complete degradation, ${ }^{8}$ and attempts to obtain crystals by solute diffusion ${ }^{13}$ were unpromising and thwarted by oxidation of glutathione.

Microanalysis and infrared spectra showed the methylmercury(II) glutathionate complex, obtained using methylmercury chloride, to be anhydrous and to have the composition $\mathrm{C}_{11} \mathrm{H}_{10^{-}}$ $\mathrm{O}_{6} \mathrm{~N}_{3} \mathrm{SHg}$ and not be in the form of a hydrochloride salt. In this complex, the methylmercury group is bonded only to the sulphur of glutathione and is free of any other intramolecular interaction in solution. This conclusion is consistent with the nature of the 1:1 complex formed by $\mathrm{CH}_{3} \mathrm{Hg}^{+}$and $N$-acetyl-L-cysteine ?

In the case of the complex obtained using a 1:1 molar ratio of glutathione and mercury(II) chloride, complexation was found to be more complicated. Examination of the elementary stoichiometric ratios revealed a chlorine to mercury ratio of 1.5 to 1.0 and provided the basis for consideration of the mixed complex, $\left[\left(\mathrm{C}_{10^{-}}\right.\right.$ $\left.\left.\mathrm{H}_{18} \mathrm{O}_{6} \mathrm{~N}_{3} \mathrm{~S}\right) \mathrm{HgCl} . \mathrm{HCl}\right]\left[\left(\mathrm{C}_{10} \mathrm{H}_{16} \mathrm{O}_{6} \mathrm{~N}_{3} \mathrm{~S}\right) \mathrm{Hg}(\mathrm{OH})\right.$.-

$\mathrm{HCl}] . \mathrm{H}_{2} \mathrm{O}$. From the calculated composition: $\mathrm{C}$ 20.75; $\mathrm{H}$ 3.22; O 19.36; $\mathrm{N}$ 7.26; $\mathrm{S} \mathrm{5.54;} \mathrm{Hg} 34.67$; Cl $9.19 \%$, monohydration was rejected on the basis of the unacceptable deviation from the oxygen analyses. The hydrogen analysis is not a sufficiently sensitive indicator for hydration in complexes of high formula weight. The \% drying loss is not reliable by itself as an indicator of hydration and is best supported by oxygen analysis. The best fit of the analytical data for the complex of glutathione obtained with $\mathrm{HgCl}_{2}$ was provided by a basic chloride, dihydrochloride formulation: $\left(\mathrm{C}_{10} \mathrm{H}_{10} \mathrm{O}_{6} \mathrm{~N}_{8} \mathrm{~S}\right)_{2}$. $\mathrm{Hg}_{2} \mathrm{Cl}(\mathrm{OH})(\mathrm{HCl})_{2}$.

For the complex obtained with glutathione and mercury(II) chloride, it would appear that precipitation of this complex in ethanolic media occurs as a double salt as suggested by elemental analysis. Upon dissolution in water, the double complex must dissociate and behave as a simple 1:1 mercury glutathionate species like that obtained using mercury(II) acetate because its solutions provide similar ${ }^{13} \mathrm{C}$ NMR spectra.

The complexes described above cannot simply be monomeric forms of the $\mathrm{Hg}_{3}(\mathrm{SR})_{2}{ }^{2-}$ complexes proposed by Kapoor et al. ' The latter were indicated at $\mathrm{pH} 7$ after the consumption of one mol of base per mol of glutathione. Kapoor et al. consider that the second equivalent of mercury in the bis complexes co-ordinates with two amino groups made available by neutralization of the ammonium ions. The complexes reported here were isolated under more acidic conditions and would not be expected to show co-ordination by free amino groups. Infrared spectra support this interpretation by the similarity of their broad $\mathrm{N}-\mathrm{H}$ stretching regions with that of glutathione.

\section{STRUCTURAL EVIDENCE BY ${ }^{18} \mathrm{C}$ NMR}

The ${ }^{13} \mathrm{C}$ NMR chemical shift evidence (Table 1) shows that in aqueous solution the glutathione complexes obtained with mercury(II) acetate and mercury(II) chloride are very similar in their structural and electronic features. As it was necessary to examine the mercury(II)

Acta Chem. Scand. B 28 (1974) No. 4 
Table 1. ${ }^{13} \mathrm{C}$ NMR chemical shifts (ppm rel. TMS) for $\mathrm{D}_{2} \mathrm{O}$ solutions of glutathione and its complexes obtained with mercury(II) acetate, methylmercury chloride, and mercury(II) chloride.

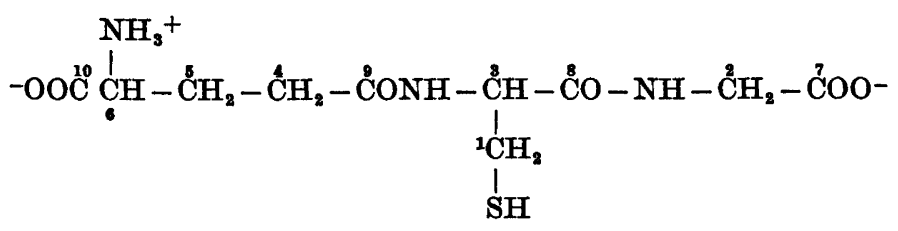

\begin{tabular}{|c|c|c|c|c|c|c|c|c|c|c|c|c|}
\hline Complex & M. Conc. ${ }^{a}$ & $\mathrm{pD}$ & 1 & 2 & 3 & 4 & 5 & 6 & 7 & 8 & 9 & 10 \\
\hline Free & 0.20 & 3.4 & 26.3 & 42.4 & 56.4 & 32.1 & 26.9 & 54.6 & 172.8 & 174.0 & 174.0 & 175.3 \\
\hline $\mathrm{Hg}(\mathrm{OAc})_{2}$ & 0.19 & 2.0 & 34.1 & 43.3 & 55.7 & 32.1 & 26.3 & 54.0 & 171.9 & 173.1 & 174.7 & 175.2 \\
\hline $\mathrm{CH}_{3} \mathrm{HgCl}^{b}$ & 0.21 & 2.2 & 29.1 & 42.1 & 57.5 & 32.1 & 26.3 & 53.7 & 172.8 & 173.3 & 173.5 & 175.0 \\
\hline $\mathrm{HgCl}_{2}{ }^{c}$ & 0.18 & 2.3 & 33.5 & 42.5 & 56.7 & 32.5 & 26.7 & 54.5 & 172.1 & - & 173.3 & 175.2 \\
\hline
\end{tabular}

$a$ Relative to glutathione; ${ }^{b} \delta_{\mathrm{CH}_{3} \mathrm{Hg}}=10.8 \mathrm{ppm} ;{ }^{c}$ Measured at $90^{\circ} \mathrm{C}$, all other samples at $37^{\circ} \mathrm{C}$.

glutathionate hydrochloride complex at $90^{\circ} \mathrm{C}$ in order to have all the sample in solution, the chemical shifts for this complex may change by approximately $1.0 \mathrm{ppm}$ due to the temperature effect.* Both mercuric complexes show a pronounced downfield shift ( $\sim 8 \mathrm{ppm})$ of the methylene carbon bearing the sulphur indicating mercurial bonding to sulphur as generally surmised. A downfield shift of $4.4 \mathrm{ppm}$ (based on noncomplexed glutathione at $\mathrm{pD}$ 7.0) was reported by Fuhr and Rabenstein ${ }^{6}$ for the cysteinyl methylene carbon of glutathione complexing with mercury(II) nitrate. Jung et al. ${ }^{14}$ reported a downfield shift of $13 \mathrm{ppm}$ for the same methylene carbon when glutathione was converted to its oxidized (S-S) form.

It is proposed that the co-ordination requirements of mercury(II) ion in our solvated mercuric complexes are satisfied by chelation to a deprotonated peptide nitrogen analogous to that

\footnotetext{
* The temperature effect was verified by examining solutions of glutathione and of the complex prepared from mercury(II) acetate at $90^{\circ} \mathrm{C}$. The ${ }^{13} \mathrm{C}$ frequencies observed for carbons numbered 2-6 in these two samples were essentially the same at those observed for the $\mathrm{HgCl}_{2}$ complex of glutathione at $90^{\circ} \mathrm{C}$. The $\mathrm{C}-1$ frequency of glutathione was shifted downfield by approximately $0.5 \mathrm{ppm}$ at $90^{\circ} \mathrm{C}$ confirming that the larger downfield shift occurring with complexation is due to mercurial bonding to sulphur. The carbonyl frequencies were not observed at $90^{\circ} \mathrm{C}$ due to increased relaxation times. Prolonged examination at $90^{\circ} \mathrm{C}$ was found to be detrimental to these samples, glutathione undergoing oxidation and the complex prepared from mercury(II) acetate discolouring intensely.
}

reported by Rabenstein ${ }^{15}$ for bis(glycylglycinato)cobaltate (III). Crystal structures of metalpeptide complexes ${ }^{16}$ would appear to rule out consideration of chelation to oxygen following lactam-lactim enolization. Two possibilities exist for such peptide nitrogen coordination with either of the amide linkages flanking the methine carbon (C-3) (see Table 1). Chelation involving the C-9 linkage would result in a 5-membered ring but should produce practically the same perturbation of C-3 as would be expected in the 6-membered ring involving chelation by the C-8 linkage. The fact that C.4 shows essentially the same frequency in the mercuric complexes both at 37 and $90{ }^{\circ} \mathrm{C}$ relative to glutathione together with the fact that C-2 for the $\mathrm{Hg}(\mathrm{OAc})_{2}$ complex shows a downfield shift at $37^{\circ} \mathrm{C}$ relative to both glutathione and its methylmercury derivative provide evidence for chelation by the C-8 peptide nitrogen. The distinction between perturbations to C-2 and C-4 appears to disappear at $90^{\circ} \mathrm{C}$ but the nature of complexation could also be altering. Additional evidence in support of this chelated structure is provided by reference to the methylmercury derivative whose C-2 and C-4 chemical shifts at $37^{\circ} \mathrm{C}$ are essentially the same as those for glutathione.

The chemical shifts for C-8 and C-9 of the complexes are assigned on a provisional basis because the differences are relatively small and because the parent frequencies are identical. The small downfield shifts for C-8 and C-9 of the methylmercury derivative of glutathione appear consistent with $\mathrm{CH}_{3} \mathrm{Hg}$ bonding to

Acta Chem. Scand. B 28 (1974) No. 4 
sulphur with no other mercurial interaction in solution with other parts of the substrate molecule. The ${ }^{13} \mathrm{C}$ chemical shifts and assignments are consistent with those reported by Jung et al. ${ }^{14}$ for glutathione and its oxidized form. Some variation in frequency is to be expected between corresponding carbon nuclei of the different complexes due to differences in dipolar and ionic interactions, hydrogen bonding and $\mathrm{pH}$; however, these effects for the carbonyl ${ }^{13} \mathrm{C}$ frequency have been estimated by Maciel and Natterstad ${ }^{17}$ to be of the order of 1 ppm.

In their study of the complexation of glutathione by $\mathrm{Cd}^{2+}$ and $\mathrm{Zn}^{2+}$, Fuhr and Rabenstein ${ }^{\circ}$ concluded from changes in the Cys-CONH carbon frequency that some binding by these ions might be occurring to the glycyl peptide linkage in addition to the sulphur atom. With mercury(II) nitrate, it was concluded that binding is exclusively to the sulphydryl group at mercury to glutathione ratios up to 0.5 with formation of a 1:2 complex. By comparison with our data (Table 1) which shows deshielding of the cysteinyl methylene carbon of glutathione by 7.8 and $2.8 \mathrm{ppm}$ for complexation with mercury(II) acetate and methylmercury chloride, respectively, it is noteworthy that the deshielding produced by complexation with mercury(II) nitrate (4.4 ppm) is more similar to that obtained with methylmercury chloride. It is not clear from the mercury(II) nitrate study whether nitrate is completely dissociated from mercury or if complexation involves ${ }^{+} \mathrm{HgNO}_{3}$ and 1:1 complex formation. Complexation of glutathione by mercury(II) acetate unquestionably involves loss of the acetate groups.

\section{EXPERIMENTAL}

A Varian XL-100-NMR spectrometer was used to obtain ${ }^{1} \mathrm{H}$ noise decoupled $25.2 \mathrm{MHz}$ Fourier transform ${ }^{13} \mathrm{C}$ NMR spectra of approxi. mately $0.2 \mathrm{M}$ deuterium oxide solutions of glutathione and of its mercury complexes. Frequencies were measured relative to dioxane and converted to the TMS scale $\left(\delta_{\text {TMS }}=\delta_{\text {dioxane }}+\right.$ $67.4 \mathrm{ppm}) .^{18}$ An accumulation time of approximately one hour was required to accumulate 1000 free induction decays (FID) each of 0.4 $\mathrm{s}$ with a pulse delay of 3.6| s. A pulse width of $80 \mu$ s was used. Off-resonance decoupling was employed to verify the chemical shifts and assignments reported by Jung et al. ${ }^{14}$ for glutathione.

Microanalyses were performed by Alfred
Bernhardt, Mikroanalytisches Laboratorium, 5251 Elbach über Engelkirchen, Fritz-PregleStrasse 14-16, W. Germany. Appropriate separatory processes were employed to eliminate interference of mercury with the $\mathrm{C}, \mathrm{H}$, and $\mathrm{Cl}$ determination. Sulphur was analyzed by a reductive process.

Mercury(II) chloride complex of glutathione, $\left(\mathrm{C}_{10} \mathrm{H}_{16} \mathrm{O}_{6} \mathrm{~N}_{3} \mathrm{~S}\right)_{2} \mathrm{Hg}_{2} \mathrm{Cl}(\mathrm{OH})(\mathrm{HCl})_{2}$. Glutathione

$(0.768 \mathrm{~g}, 0.0025 \mathrm{~mol}$, Sigma, reduced form) was dissolved in warm $\left(50^{\circ} \mathrm{C}\right) 95 \%$ ethanol $(10 \mathrm{ml})$ with magnetic stirring by adding just sufficient water $(8 \mathrm{ml})$ for dissolution. A solution of mercury(II) chloride $(0.679 \mathrm{~g}, 0.0025 \mathrm{~mol}, \mathrm{BDH}$ Analar) in $95 \%$ ethanol $(10 \mathrm{ml})$ was added dropwise to the stirred glutathione solution. Precipitation occurred immediately, but the solid readily dissolved with stirring except near the end of the addition when a flocculent precipitate persisted. When the last few drops of $\mathrm{HgCl}_{2}$ solution were added, the mixture formed a white slurry. When a white gum appeared after 5 min of stirring and cooling, the mixture was treated with water. Immediate clarification of the supernatant occurred, and the mixture was treated periodically with water (total $20 \mathrm{ml}$ ) until all gum had dissolved with stirring at room temperature. Finely divided solid was obtained from the mixture after refrigeration for $4 \mathrm{~h}$. The solid was collected, washed with $95 \%$ ethanol and dried over $\mathrm{NaOH}$ in vacuo. The yield of product was $1.03 \mathrm{~g}$ or $73 \%$. The product was found to be appreciably soluble in water. IR spectra $\left(4000-600 \mathrm{~cm}^{-1}\right)$ appeared to be little different from glutathione, and X-ray diffraction patterns showed the product to be amorphous. (Found: C 21.25; H 3.41; O 18.47, 18.66, 18.62; N 7.20; S 5.58; Hg 34.84, 34.04; Cl 9.09, 9.07, 9.12; and drying loss $\left(50^{\circ} \mathrm{C} / \mathrm{HV}\right), 3.11 \%$. $\left(\mathrm{C}_{10} \mathrm{H}_{16} \mathrm{O}_{6} \mathrm{~N}_{3} \mathrm{~S}\right)_{2} \mathrm{Hg}_{2} \mathrm{Cl}(\mathrm{OH})(\mathrm{HCl})_{2}$ (M.W. 1139.26) requires $\mathrm{C} 21.08$; $\mathrm{H}$ 3.10; $\mathrm{O}$ 18.26; $\mathrm{N}$ 7.38; $\mathrm{S}$ 5.63; Hg 35.22; Cl 9.34.)

Mercury (II) glutathionate monohydrate, $\left(\mathrm{C}_{10}\right.$ $\left.\mathrm{H}_{15} \mathrm{O}_{6} \mathrm{~N}_{3} \mathrm{~S}\right) \mathrm{Hg} . \mathrm{H}_{2} \mathrm{O}$. Glutathione $(0.768 \mathrm{~g}, 0.0025$ mol, Sigma, reduced form) was dissolved at room temperature in water $(20 \mathrm{ml})$ and $95 \%$ ethanol $(10 \mathrm{ml})$, then the solution was warmed to $40^{\circ} \mathrm{C}$. To this solution, a warm $\left(40^{\circ} \mathrm{C}\right)$ solution of mercury(II) acetate $(0.797 \mathrm{~g}, 0.0025 \mathrm{~mol}$, Merck) in methanol $(10 \mathrm{ml})$ was added dropwise with magnetic stirring. Precipitation occurred immediately and persisted gradually producing coagulated spherical masses. Towards the end of the addition a milky suspension was obtained. On cooling to room temperature, the mixture lost its stickiness and the solid could be easily pulverized in the presence of the supernatant liquid. When the solid was found to be extremely difficult to filter with suction due to clogging of the paper, it was collected by slow filtration using a fluted paper. The very finely divided, powdery solid was washed with acetone and dried over $\mathrm{NaOH}$ in vacuo. The yield was 0.97 $\mathrm{g}$ or $75 \%$. The solid is insoluble in water at room temperature, but it dissolves readily on 
addition of a drop of $12 \mathrm{M} \mathrm{HCl}$ or trifluoroacetic acid. Infrared spectra showed the absence of acetyl $\mathrm{C}=\mathrm{O}$ stretching, otherwise, the spectral features $\left(4000-600 \mathrm{~cm}^{-1}\right)$ are very similar to those of glutathione. X-Ray diffraction patterns showed the solid to be amorphous. (Found: $C$ 23.05; H 3.48; O 21.36; N 7.96; S 6.14; Hg 38.23; drying loss $\left(50{ }^{\circ} \mathrm{C} / \mathrm{HV}\right)$, 3.23. $\left(\mathrm{C}_{10} \mathrm{H}_{18} \mathrm{O}_{6} \mathrm{~N}_{3} \mathrm{~S}\right)$; $\mathrm{Hg} . \mathrm{H}_{2} \mathrm{O}$ (M.W. 524.14) requires C 22.90; $\mathrm{H} \mathrm{3.27}$; $\mathrm{O} 21.37$; N 8.02; S 6.12; Hg 38.27, and drying loss, $3.44 \%$ ).

Methylmercury glutathionate, $\left(\mathrm{C}_{10} \mathrm{H}_{16} \mathrm{O}_{6} \mathrm{~N}_{3} \mathrm{~S}\right)$ $\mathrm{HgCH}_{3}$. CAUTION: Use well-ventilated hood and exercise precautions with alkyl mercury. ${ }^{19}$

A solution of glutathione $(0.768 \mathrm{~g}, 0.0025 \mathrm{~mol}$, Sigma reduced form) was prepared in water (10 ml) with slight warming and then diluted with $95 \%$ ethanol $(10 \mathrm{ml})$. A saturated solution of methylmercuric chloride $(0.627 \mathrm{~g}, 0.0025 \mathrm{~mol}$, Alfa Inorganics) was prepared in $95 \%$ ethanol $(40 \mathrm{ml})$. The mercurial solution was added quickly since no precipitation or "tail-effect" formed during addition. The small portion of undissolved $\mathrm{CH}_{3} \mathrm{HgCl}$ was transferred to the reaction mixture during washing with ethanol. No precipitation occurred following the addition nor on standing of the mixture.

After treating the mixture with acetone until turbid and refrigerating it, a flocculent white solid was collected, washed with acetone and dried over $\mathrm{NaOH}$ in vacuo (Fr. A, 0.212 g). The mother liquor was reduced to about $10 \mathrm{ml}$ by rotary evaporation, then it was treated with diethyl ether to obtain turbidity - some acetone had to be added to maintain miscibility - however, an oil formed. Slight warming and addition of ethanol produced no beneficial effect. On standing overnight, the syrupy residue hardened to a gum. The mixture was then heated until the gum dissolved. When the solution had cooled to room temperature ether was added slowly and periodically over a $4 \mathrm{~h}$ period to maintain a light turbidity. Solid (Fr. B, 0.445 g) was then obtained following refrigeration. The mother liquor, on evaporation in a petri dish in a fume hood, gave a hard, glassy residue (Fr. C, 0.358 g). Fractions A and B contracted in volume appreciably during drying in vacuo (20 $\mathrm{mmHg}$ ) at room temperature, but there appeared to be no evidence for sublimation. Each fraction was found to be amorphous by X-ray diffraction, and infrared spectra were rather similar to spectra of glutathione. (Found: C 25.40; H 3.98; O 18.33; N 7.88; S 6.05; Hg 38.47. $\mathrm{C}_{11} \mathrm{H}_{19} \mathrm{O}_{6} \mathrm{~N}_{3} \mathrm{SHg}$ (M.W. 521.96) requires C 25.31; H 3.69; O 18.39; N 8.05; S 6.14; Hg 38.45.)

Acknowledgement. The interest of Prof. Maths Berlin, Institute of Hygiene, University of Lund, Sweden in encouraging structural studies related to mercurial toxicology and biotransformation is gratefully acknowledged. Special appreciation is extended of Prof. Börje Wickberg, Organic Chemistry 2, Chemical Center,
University of Lund, Sweden, for provision of laboratory space and resources. The interest and help of Dr. Lars Haraldson, Analytical Chemistry, University of Lund, Sweden, in discussing various aspects of microanalytical data is warmly acknowledged. The Medical Research Council of Canada is generously thanked for the provision of a Centennial Fellowship and research grant in support of this work. The Swedish Natural Science Research Council is also thanked for continuing financial support for instrumental resources at the Chemical Centre.

\section{REFERENCES}

1. Cantarow, A. and Schepartz, B. Biochemistry, Saunders, Philadelphia 1962, pp. 390, 563,803 and 811 .

2. Nordberg, G. F. and Skerfving, S. Metabolism. In Friberg, L. and Vostal, J., Eds., Mercury in the Environment, The Chemical Rubber Co., Cleveland 1972, pp. 29-91.

3. Weed, R., Eber, J. and Rothstein, A. $J$. Gen. Physiol. 45 (1962) 395.

4. Stricks, W. and Kolthoff, I. M. J. Amer. Chem. Soc. 75 (1953) 5673.

5. Kapoor, R. C., Doughty, G. and Gorin, G. Biochim. Biophys. Acta 10 (1965) 376.

6. Fuhr, B. J. and Rabenstein, D. L. J. Amer. Chem. Soc. 95 (1973) 6944.

7. Simpson, P. G., Hopkins, T. E. and Haque, R. J. Phys. Chem. 77 (1973) 2282.

8. Neville, G. A. and Berlin, M. Can. J. Chem. 51 (1973) 3970.

9. Birgersson, B., Drakenberg, T. and Neville, G. A. Acta Chem. Scand. 27 (1973) 3953.

10. Neville, G. A. and Drakenberg, T. Can. J. Chem. 52 (1974) 616.

11. Johansson, G. Acta Chem. Scand. 25 (1971) 1905.

12. Björnlund, G. Acta Chem. Scand. 25 (1971) 1645.

13. Stout, G. H. and Jensen, L. H. In X-Ray Structure Determination, $A$ Practical Guide, MacMillan, New York 1968, p. 65.

14. Jung, G., Breitmaier, E., Voelter, W., Keller, T. and Tänzer, C. Angew. Chem. Int. Ed. Engl. 9 (1970) 894; Jung, G., Breitmaier, E. and Voelter, W. Eur. J. Biochem. 24 (1972) 438.

15. Rabenstein, D. L. Can. J. Chem. 49 (1971) 3767.

16. Freeman, H. C. Advan. Protein Chem. 22 (1967) 257.

17. Maciel, G. E. and Natterstad, J. J. J. Chem. Phys. 42 (1965) 2752.

18. Johnson, L. F. and Jankowski, W. C. In Carbon-13 NMR Spectra, Wiley, New York 1972.

19. Klein, R. and Herman, S. Science 172 (1971) 872.

Received December 10, 1973.

Acta Chem. Scand. B 28 (1974) No. 4 